\title{
Design of Toroid-Shaped Solid Ceramic End Mill
}

\author{
Vladimir Grechishnikov ${ }^{1}$, Sergey Grigoriev ${ }^{1}$, Petr Pivkin ${ }^{1}$, Marina Volosova ${ }^{1}$, Alexander Isaev ${ }^{1}$, Dmitry Nikitin ${ }^{1}$ and Ilya \\ Minin $^{1}$ \\ ${ }^{1}$ Moscow State Technological University "STANKIN", RU-127055, Moscow, Russia
}

\begin{abstract}
Electrical discharge machining (EDM) is one of the most accurate methods for machining conductive materials and has a number of important applications. In the EDM process the occurrence of electric charges between cathode and anode is accompanied by vibroacoustic signals, which can be used to develop highly efficient control and diagnostics systems. Experimental studies and modelling of the dynamic system of the EDM process carried out in this study show that parameters of acoustic signals can be used to estimate the current productivity and risks of the tool-electrode breakage and to optimize the tool feed rate. The obtained results of allows using acoustic signals in the control system of the tool electrode feed rate to prevent its breakage, and also setting the interelectrode gap to maximum productivity.
\end{abstract}

\section{Introduction}

Solid ceramic end mills are an innovative solution, with the first patents by Kennametal dating back to year 2014 [1]. They are typically used for highly efficient cutting of workpieces made from hard-to-cut structural materials, such as heat-resistant nickel alloys, etc[2-11]. The primary use of such mills is manufacturing the critical components in aviation, aerospace, and special engineering industries. The development of novel approaches to the design and maintenance of such cutting tools is a scientific and technical task of extreme importance and should allow a significant growth of cutting efficiency.

Relevance of ceramic solid end mills for machining heat-resistant materials was confirmed in ref. [12]. Reduced cutting forces, increased tool life when using ceramic end mills in comparison with carbide mills, and improved machined surface quality were obtained in [13].

The recent work [14] shows that solid ceramic end mills can be used with a cutting speed of 5 times higher than with carbide tools when machining nickel alloys, especially for high-performance machining methods, e. g. when machining crucial components used in aviation and aerospace products.

In the recent study [12], a description of producing a blank part from nanostructured ceramics using spark plasma sintering process, and manufacturing a sample solid ceramic end mill, as well as a detailed description of the cutting tools design, were given

Difficulties accompanying cutting of heat-resistant nickel-based alloys are due to their low heat conductivity, tendency to self-hardening during cutting, and chip shape (continuous or semi-continuous) [15]. These factors contribute to the formation of high temperatures and specific tangential cutting forces on the rake surface of the end mill, and to the high temperatures on the flank surface in the case when cutting wedge is sharp. It has been found that the predominant types of wear during machining of heat-resistant nickel alloys are plastic deformation or wear along the flank surface and chipping at the cutting depth. Wear criterion is the size of flank wear-land. The use of cutting ceramics, which, has higher wear and heat resistance compared to tungsten carbides, can significantly reduce plastic deformation and / or flank wear.

At the same time, it is recommended to use negative rake angles to increase the strength of the cutting wedge made of brittle ceramics, while eliminating chipping caused by self-hardening of the machined material, it is advisable to reduce the axial depth of cut when face milling strategy, or use the smallest possible lead angle [2, 3, 8-15]. For this purpose, as well as to increase the strength of the most loaded section at the transition from the peripheral to the end cutting edge[16, 19], solid ceramic end mills are equipped with a corner radius. Due to this, a toroidal section of mill generating surface is formed.

One of the main reasons for the solid ceramic end mills functional failure is the low structural strength of the tool. The helical surface of the cutting part, passing from the cylindrical periphery to the mill, has a uniform load distribution without stress concentrators on the toroidal section of mill generating surface. The behaviour of the cutting edge inclination angle and the wedge angle along the profile on the toroidal section allow us to vary the distribution of forces and residual stresses in the cutting material.

The study of geometric parameters on the toroidal part is aimed at analysing the actual geometric configuration of the cutter's end part without thinning on the rake surface in order to identify the possibility of increasing the structural strength of the cutting edge and

e-mail: pmpivkin@gmail.com

(C) The Authors, published by EDP Sciences. This is an open access article distributed under the terms of the Creative Commons Attribution License 4.0 
the creating the cutting part with an optimal values of the rake angles in all normal sections to the cutting edge on the toroidal surface[16-21].

The mathematical model end mill's rake surface profile on toroidal section was based on mathematical dependencies (1) The initial data for the model were the parameters $K_{1}, K_{2}, K_{3}$ setting the position of the main profile elements of the abscissa axis.

$$
\begin{gathered}
a=F\left(K_{1}, K_{2}, K_{3}\right) \\
b=F\left(K_{2}, K_{3}\right) \\
K_{1}=-1.29 \\
K_{2}=0
\end{gathered}
$$

$K_{3}$

$=\frac{\sqrt{R_{k o n t r}^{2}+k^{2}-R_{z a g}{ }^{2}+R_{k o n t r}^{2}}-R_{z a g} * k}{k^{2}+1}$

On the ordinate axis, the points were expressed through their radial position relative to the center of the workpiece (2)

$$
\begin{gathered}
\mathrm{Y}_{\mathrm{k} 1}=\sqrt{\mathrm{R}_{\text {serd }}{ }^{2}-\mathrm{K}_{1}^{2}} \\
\mathrm{Y}_{\mathrm{k} 2}=\mathrm{R}_{\mathrm{zag}}
\end{gathered}
$$

$\mathrm{Y}_{\mathrm{k} 3}$

$$
\begin{aligned}
& =\frac{\sqrt{\mathrm{R}_{\mathrm{kontr}}^{2}+\mathrm{k}^{2}-\mathrm{R}_{\mathrm{zag}}{ }^{2}+\mathrm{R}_{\mathrm{kontr}}{ }^{2}}-\mathrm{R}_{\mathrm{zag}} * \mathrm{k}}{\mathrm{k}^{2}+1} \\
& +\mathrm{R}_{\mathrm{zag}}
\end{aligned}
$$

Based on the obtained data, the equations of profile end mill's radial section were formed (3):

$$
\begin{gathered}
\mathrm{PP}(\mathrm{X})=\mathrm{b}+\sqrt{2 * \mathrm{a} * \mathrm{X}-\mathrm{X}^{2}+\mathrm{R}_{\mathrm{pp}}^{2}-\mathrm{a}^{2}} \\
\mathrm{D}_{\text {kontr }}(\mathrm{X})=\sqrt{\mathrm{R}_{\mathrm{kontr}}^{2}-\mathrm{X}^{2}} \\
\mathrm{D}_{\mathrm{zag}}(\mathrm{X})=\sqrt{\mathrm{R}_{\mathrm{zag}}^{2}-\mathrm{X}^{2}} \\
\mathrm{D}_{\text {serd }}(\mathrm{X})=\sqrt{\mathrm{R}_{\text {serd }}^{2}-\mathrm{X}^{2}} \\
\operatorname{Kas}(\mathrm{X})=\mathrm{k} * \mathrm{X}+\mathrm{R}_{\mathrm{zag}}
\end{gathered}
$$

where: $P P(X)$ - approximated profile curve of the rake surface, $D_{\text {kontr }}$ - control diameter, $D_{z a g}(X)$ - workpiece diameter, $\operatorname{Kas}(X)$ - tangent line to rake surface, $D_{\text {serd }}-$ mill's core diameter.

The profile graph is shown in image 1 .

The rake surface of a solid ceramic mill is formed in a radial section considering the recommended negative rake angle. The profile of the rake surface with a rake angle $\gamma=-10^{\circ}$ in the $X O Y$ coordinate system is represented by dependence (1):

$$
\begin{aligned}
& F_{p p 1}(X) \\
& =b(\gamma)-\sqrt{2 \cdot a(\gamma) \cdot X-X^{2}+R_{p p}-a(\gamma)^{2}}
\end{aligned}
$$

$$
\mathrm{F}_{\mathrm{pp}}(\mathrm{X}, \mathrm{v})=\left(\begin{array}{c}
\mathrm{X} \cdot \cos (\mathrm{v})-\sin (\mathrm{v}) \cdot\left(\mathrm{F}_{\mathrm{pp} 1}\right) \\
\cos (\mathrm{v}) \cdot\left(\mathrm{F}_{\mathrm{pp} 1}\right)+\mathrm{X} \cdot \sin (\mathrm{v}) \\
\left(\frac{\mathrm{T}}{2 \pi}\right) \cdot \mathrm{v}
\end{array}\right)
$$

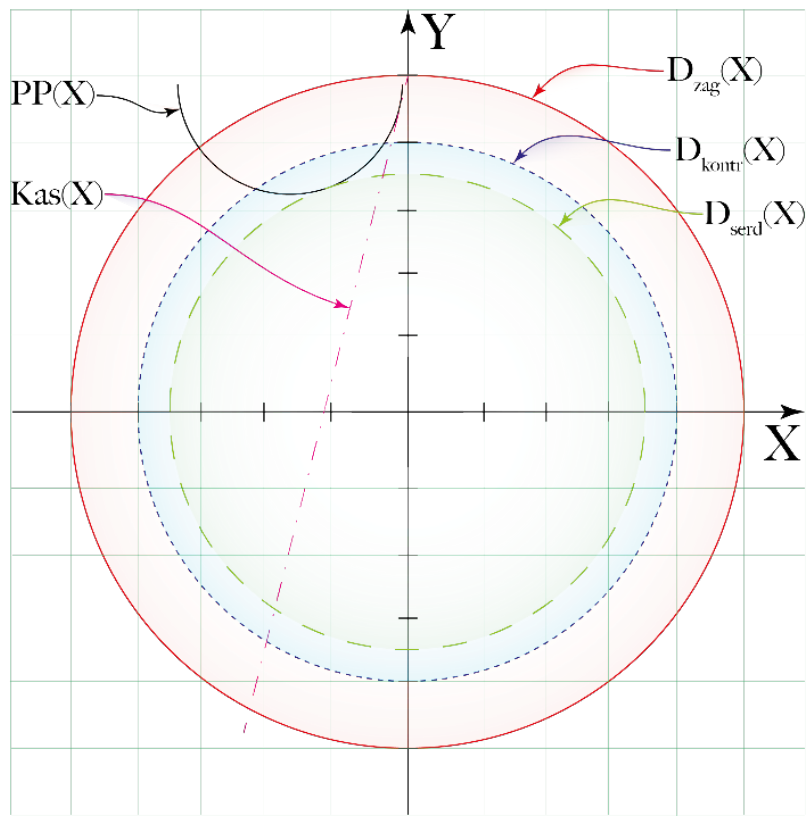

Fig. 1. Shape model of toroidal section end mill's rake surface.

where $a(\gamma), b(\gamma)$ are the characteristics of the rake surface profile on the $X O Y$ plane, considering the value of the rake angle in the cutter radial section (Fig. 2).

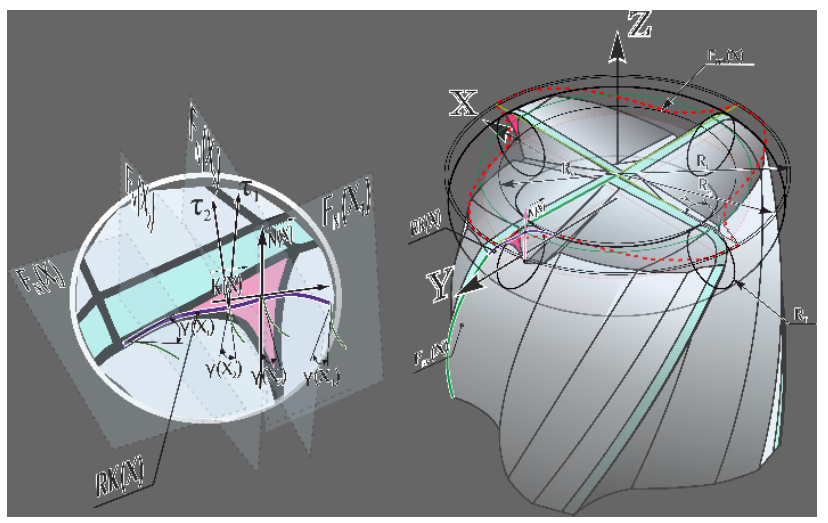

Fig. 2. Main geometrical parameters of toroid-shaped solid ceramic end mill

The shape of the cutting edge is defined as the spatial line of intersection of the producing toroidal surface (3) with the helical rake surface (4). 


$$
\begin{aligned}
& F_{T}(X, Y) \\
& =\sqrt{R_{T}{ }^{2}-R_{f}^{2}-X^{2}-Y^{2}+2 R_{f} \sqrt{X^{2}+Y^{2}}}
\end{aligned}
$$

$$
\begin{gathered}
\mathrm{G}_{1} \\
=\sqrt{\mathrm{R}_{\mathrm{pp}}^{2}-(\mathrm{X}+\Delta \mathrm{X})^{2}-\mathrm{a}(\gamma)^{2}+a(\gamma) \cdot(2 \mathrm{X}+2 \Delta \mathrm{X})} \\
\mathrm{G}_{1} \mathrm{XR}_{\mathrm{f}}=\mathrm{G}_{1}+2 \cdot \mathrm{a}(\gamma)(2 \mathrm{X}+2 \Delta \mathrm{X})-2 \mathrm{R}_{\mathrm{f}} \cdot \mathrm{G}_{1}
\end{gathered}
$$

$\mathrm{G}_{2}$

$$
=\sqrt{-\frac{\mathrm{R}_{\mathrm{pp}}^{2}+\mathrm{R}_{\mathrm{f}}^{2}-\mathrm{R}_{\mathrm{T}}^{2}-\mathrm{a}(\gamma)^{2}+\mathrm{b}^{2}-2 \mathrm{~b}(\gamma) * \mathrm{G}_{1} \mathrm{XR}}{\mathrm{T}(\omega)^{2}}}
$$

$$
\begin{aligned}
& \mathrm{RK}_{\mathrm{X}}(\mathrm{X})=\mathrm{X} \cdot \cos \left(2 \pi \cdot \mathrm{G}_{2}\right) \\
& \quad-\sin \left(2 \pi \cdot \mathrm{G}_{2}\right) \cdot\left(\mathrm{b}-\mathrm{G}_{1}\right) \\
& \quad \mathrm{RK}_{\mathrm{Y}}(\mathrm{X})=\mathrm{X} \cdot \sin \left(2 \pi \cdot \mathrm{G}_{2}\right) \\
& \quad+\cos \left(2 \pi \cdot \mathrm{G}_{2}\right) \cdot\left(\mathrm{b}-\mathrm{G}_{1}\right)
\end{aligned}
$$

$$
\mathrm{RK}_{\mathrm{Z}}(\mathrm{X})=\mathrm{T}(\omega) \cdot \mathrm{G}_{2}
$$

$$
R K(X)=\left[\begin{array}{l}
\mathrm{RK}_{\mathrm{X}}(\mathrm{X}) \\
\mathrm{RK}_{\mathrm{Y}}(\mathrm{X}) \\
\mathrm{RK}_{\mathrm{Z}}(\mathrm{X})
\end{array}\right]
$$

The evaluation of the cutting conditions and operational parameters of the cutting tool is carried out in the normal section FN (XN) (6). A single surface FN (XN) normal to the cutting edge is built basing on the tangent vector $\vec{K}$ to the cutting edge at the point defined by equation (8). Concurrently, the vector $\vec{K}$ is a normal vector to the plane of the normal cutting edge.

$$
\overrightarrow{\mathrm{K}}(\mathrm{X})=\left(\begin{array}{l}
\overrightarrow{\mathrm{K}}_{\mathrm{X}}(\mathrm{X}) \\
\overrightarrow{\mathrm{K}}_{\mathrm{Y}}(\mathrm{X}) \\
\overrightarrow{\mathrm{K}}_{\mathrm{Z}}(\mathrm{X})
\end{array}\right)
$$

$$
\begin{gathered}
\operatorname{RKVek}_{\mathrm{X}}=\left(\mathrm{X}_{1}-\mathrm{RK}_{\mathrm{X}}(\mathrm{X})\right) \cdot\left(\mathrm{RK}_{\mathrm{X}}(\mathrm{X})-\operatorname{Vek}_{\mathrm{X}}(\mathrm{X})\right) \\
\operatorname{RKVek}_{\mathrm{Y}}=\left(\mathrm{Y}_{1}-\mathrm{RK}_{\mathrm{Y}}(\mathrm{X})\right) \cdot\left(\mathrm{RK}_{\mathrm{Y}}(\mathrm{X})-\operatorname{Vek}_{\mathrm{Y}}(\mathrm{X})\right) \\
\operatorname{RKVek}_{\mathrm{Z}}=\left(\mathrm{Y}_{1}-\mathrm{RK}_{\mathrm{Z}}(\mathrm{X})\right) \cdot\left(\mathrm{RK}_{\mathrm{Z}}(\mathrm{X})-\operatorname{Vek}_{\mathrm{Z}}(\mathrm{X})\right) \\
\mathrm{F}_{\mathrm{N}}\left(\mathrm{X}_{1}, \mathrm{Y}_{1}\right)=-\frac{\mathrm{RKVek}_{\mathrm{X}}+\mathrm{RKVek}_{\mathrm{Y}}+\mathrm{RKVek}_{\mathrm{Z}}}{\mathrm{RK}_{\mathrm{Z}}(\mathrm{X})-\operatorname{Vek}_{\mathrm{Z}}(\mathrm{X})}
\end{gathered}
$$

To estimate the rake angle in normal sections $\gamma_{N}$ along the cutting edge, a section is formed on the rake surface described by the parametric function (7). The control point on the rake surface at which the normal rake angle can be measured is determined by solving the transcendental equation for $v \Rightarrow v_{r}$ obtained by substituting parameters (11) in (10).

$$
V(v)=\left(\begin{array}{c}
Q_{X}(\gamma) \cdot \cos (v)-Q_{Y}(\gamma) \cdot \sin (v) \\
Q_{Y}(\gamma) \cdot \cos (v)+Q_{X}(\gamma) \cdot \sin (v) \\
\left(\frac{T(\omega)}{2 \pi}\right) \cdot v
\end{array}\right)
$$

The rake angle in normal sections $\gamma_{\mathrm{N}}$ is quantified by the equation for finding the cosine of the angle between nonzero vectors (11). One of these vectors is tangent to the rake surface $\tau_{1}(12)$, and other is normal to the toroidal surface at a control point on the cutting edge

$$
\tau_{2}(13) \cdot \gamma_{\mathrm{N}}=\operatorname{acos}\left(\frac{\overrightarrow{\overrightarrow{1}_{1}} \cdot \overrightarrow{\tau_{2}}}{\left|\overrightarrow{\tau_{1}}\right| \cdot\left|\cdot \overrightarrow{\tau_{2}}\right|}\right)
$$

$$
\tau_{1}=\left(\begin{array}{l}
\mathrm{RK}_{\mathrm{X}}\left(\mathrm{X}_{\mathrm{N}}\right)-\mathrm{V}_{\mathrm{X}}\left(\mathrm{v}_{\mathrm{r}}\right) \\
\mathrm{RK}_{\mathrm{Y}}\left(\mathrm{X}_{\mathrm{N}}\right)-\mathrm{V}_{\mathrm{Y}}\left(\mathrm{v}_{\mathrm{r}}\right) \\
\mathrm{RK} \mathrm{Z}\left(\mathrm{X}_{\mathrm{N}}\right)-\mathrm{V}_{\mathrm{Z}}\left(\mathrm{v}_{\mathrm{r}}\right)
\end{array}\right)
$$

$$
\tau_{2}=\left(\begin{array}{c}
\mathrm{RK}_{\mathrm{X}}\left(\mathrm{X}_{\mathrm{N}}\right)-\mathrm{Vc}_{\mathrm{X}}\left(\mathrm{v}_{\mathrm{r}}\right) \\
\mathrm{RK}_{\mathrm{Y}}\left(\mathrm{X}_{\mathrm{N}}\right)-\mathrm{Vc}_{\mathrm{Y}}\left(\mathrm{v}_{\mathrm{r}}\right) \\
\mathrm{RK}_{\mathrm{Z}}\left(\mathrm{X}_{\mathrm{N}}\right)
\end{array}\right)
$$

where $\mathrm{Vc}_{\mathrm{X}}\left(\mathrm{v}_{\mathrm{r}}\right), \mathrm{V} \mathrm{c}_{\mathrm{Y}}\left(\mathrm{v}_{\mathrm{r}}\right)$ are equal to:

$$
\begin{aligned}
& \mathrm{Vc}_{\mathrm{X}}=\frac{\mathrm{R}_{\mathrm{f}} \cdot \mathrm{RK}_{\mathrm{X}}\left(\mathrm{X}_{\mathrm{N}}\right)}{\sqrt{\left(\mathrm{RK}_{\mathrm{X}}\left(\mathrm{X}_{\mathrm{N}}\right)\right)^{2}+\left(\mathrm{RK}_{\mathrm{Y}}\left(\mathrm{X}_{\mathrm{N}}\right)\right)^{2}}} \\
& \mathrm{Vc}_{\mathrm{Y}}=\frac{\mathrm{R}_{\mathrm{f}} \cdot \mathrm{RK}_{\mathrm{Y}}\left(\mathrm{X}_{\mathrm{N}}\right)}{\sqrt{\left(\mathrm{RK}_{\mathrm{X}}\left(\mathrm{X}_{\mathrm{N}}\right)\right)^{2}+\left(\mathrm{RK}_{\mathrm{Y}}\left(\mathrm{X}_{\mathrm{N}}\right)\right)^{2}}}
\end{aligned}
$$

The mathematical model of the cutting part allows to estimate the distribution of normal rake angle values along the cutting edge. This model is built basing on the identified functional relationships between the geometric parameters of the ceramic end mill $\left(\gamma=-14^{\circ}, R_{F}=\right.$ $5 \mathrm{~mm}, R_{S}=4 \mathrm{~mm}$ ) with a corner radius $\mathrm{R}_{\mathrm{t}}=1 \mathrm{~mm}$. It is revealed that the rake angle varies along the cutting edge from $-14^{\circ}$ to $-35^{\circ}$ (Fig. 3). This distribution is not rational. With the rake angle reduction, the load on the cutting part increases and, thus, the tool breakage probability also increases. The rational values of the normal rake angle were determined based on strength assessment by finite element analysis performed in the ANSYS Workbench environment. 


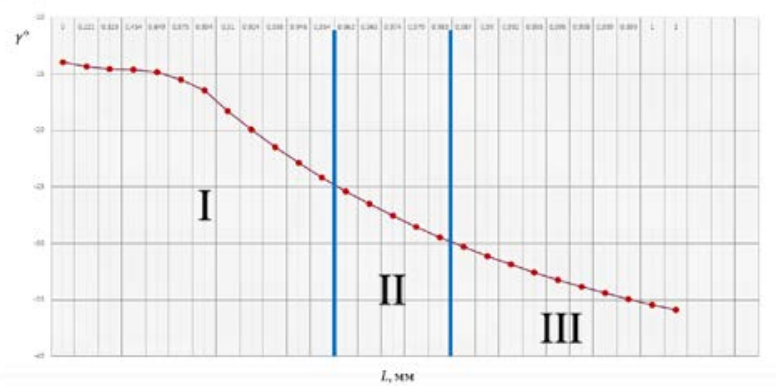

Fig. 3. Variation of normal rake angle on toroidal forming surface from mill's face on XOY grafic plot

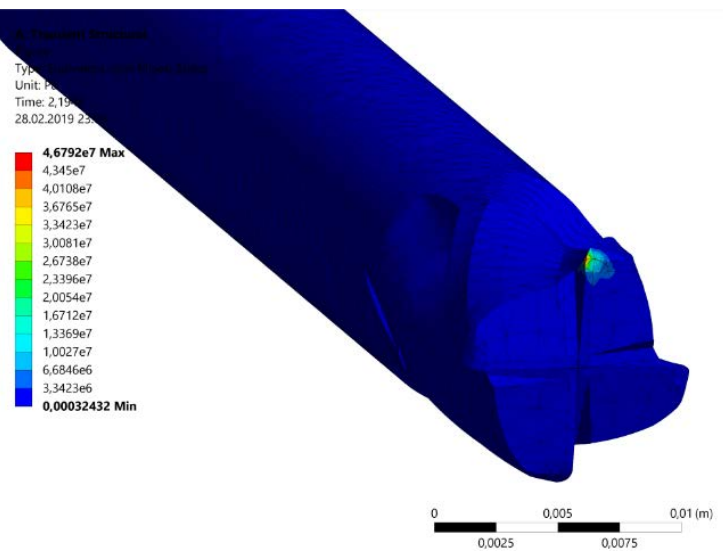

Fig. 4. Solution of finite-element deformation modeling on helical rake of end mill surface in ANSYS WB

In Fig. 4, the cutting forces distribution on the rake surface in accordance with the effective cutting patterns is shown. As a result of finite element modeling, 3 different cutter designs with each range of angle values presented in Fig. 3 were studied. It was revealed that the cutter designs from range I $\left(\gamma=-14^{\circ} \ldots-24^{\circ}\right)$ are less susceptible to brittle fracture. Cutter design from range II $\left(\gamma=-24^{\circ} \ldots-30^{\circ}\right)$ are in the transition range with an increased probability of breakage. Last, the cutter designs from range III $\left(\gamma<-30^{\circ}\right)$ have an increased breakage probability due to a significant increase in cutting forces.

\section{Conclusion}

The results of finite element modeling and analysis of the mill's geometric parameters confirm the need to create a specialized thinning (undercut) on the toroidal section of the cutting part because of unstable range of internal stresses.

Definition of the starting point of the thinning can be made based on dependencies (11-13). For ceramic end milling cutter with basic geometric parameters $\left(\gamma=-14^{\circ}, \quad R_{F}=5 \mathrm{~mm}, R_{S}=4 \mathrm{~mm}\right)$ and with a toroidal part having a radius of curvature $R_{t}=1 \mathrm{~mm}$, the thinning must be performed by grinding at a distance of $0.754 \mathrm{~mm}$ from the beginning of the toroidal surface. The advanced design of solid ceramic end mill with a special thinning will form= uniform distribution of rake angles along the cutting edge, improve cutting conditions and, thus, increase tool life and processing productivity.

Acknowledgements. We would like to thank the Russian Science Foundation for supporting this work under grant № 18 19-00599 RSF. This work was carried out using equipment provided by the Center of Collective Use of MSUT "STANKIN".

\section{References}

1. D.R. Davis, S.E. Landwehr, RL. Yeckley (2014). United States Patent № 8647025 B2, Monolithic Ceramic end mill Appl. No 13/007,840 Kennametal Inc., Latrobe, PA (US)

2. S.N. Grigoriev, V.D. Gurin, M.A. Volosova, and N. Y. Cherkasova, Materialwiss. Werkstofftech., 44(9), 790-796 (2013).

3. S.N. Grigoriev, M.P. Kozochkin, F.S. Sabirov, and A.A. Kutin, Proc. CIRP, 1, 599-604 (2012).

4. V. Bushlya, J. Zhou and J. E. Ståhl, Procedia CIRP, 3, 370-375 (2012).

5. Q. Wang, Z. Liu, B. Wang, Q. Song, Y. Wan, Int J Adv Manuf Technol 82(9-12), 1725-1736 (2016)

6. S.N. Grigoriev, V.A. Sinopalnikov, M.V. Tereshin, and V.D. Gurin, Measur. Techn., 55(5), 555-558 (2012).

7. A. Saini, S. Dhiman, R. Sharma and S. Setia, Journal of Mechanical Science and Technology, 28(6), 2307-2318 (2014)

8. X. Jiang, W. Xiong, L. Wang, M. Guo \& Z. Ding, Mat. Sci. and Tech., (2019) DOI: 10.1080/02670836.2019.1685770

9. S. Grigoriev, A. Vereschaka, A. Metel, N. Sitnikov, F. Milovich, N. Andreev, S. Shevchenko, Y. Rozhkova, Coatings, 8(12), 447 (2018)

10. M. Anthony Xavior, M. Manohar, P.M. Madhukar, et al. J Mech Sci Technol 31, 4789 (2017) https://doi.org/10.1007/s12206-017-0926-2.

11. X. Liang, Z. Liu, Wang, X. Hou, Int J Mech Sci 140, 1-12 (2018)

12. S.N. Grigoryev, V.A. Grechishnikov, M.A. Volosova, A.V. Isaev, P.M. Pivkin, Vestnik MGTU Stankin 4(47), 87-93 (2018) [in Russian]

13. R.M. Khusainov, S.Yu. Yurasov, R.R. Ziyatdinov, G.K. Davletshina et al., STIN 9. 32-35 (2016) [in Russian]

14. B. Wang, Z. Liu, Int. Journal of Refractory Metals and Hard Materials, 55, 24-32 (2016)

15. M. Sajgalik et al., Procedia Manufacturing 14(2), 51-57 (2017)

16. A. Isaev, V.A. Grechishnikov, P.M. Pivkin, M.P. Kozochkin et al., Procedia CIRP 48, 1023 1026 (2016)

17. S.N. Grigoriev, G.M. Martinov, Proc. CIRP, 41, 858-863 (2016) 
18. A. Zelensky, V. Voronin, I. Svirin, E. Semenishchev, A. Alepko, Proceedings of the IEEE International Conference on Smart Cloud 208212 (2018)

19. V.A. Grechishnikov, S.N. Grigoriev, P.M. Pivkin Development of the design of the whole end ceramic mill with toroidal cutting form STIN 7, 31-35 (2019).

20. S.N. Grigoriev, G.M. Martinov, Proc. CIRP, 14, 517-522 (2014)

21. X. Jiang, X. Kong, Z. Zhang, Z. Wu, Z. Ding, M. Guo., Int. Journal of Mech. Sci., 167, 105162 (2020)

doi: https://doi.org/10.1016/j.ijmecsci.2019.105162 